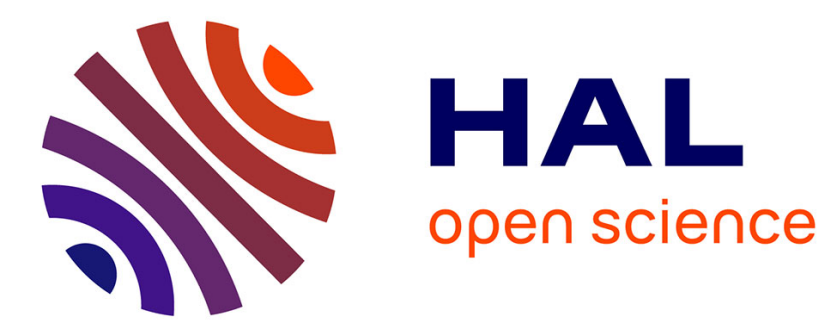

\title{
Extended liver resections for intrahepatic cholangiocarcinoma: Friend or foe?
}

Damien Bergeat, Laurent Sulpice, Michel Rayar, Julien Edeline, Aude Merdignac, B. Meunier, Eveline Boucher, Karim Boudjema

\section{To cite this version:}

Damien Bergeat, Laurent Sulpice, Michel Rayar, Julien Edeline, Aude Merdignac, et al.. Extended liver resections for intrahepatic cholangiocarcinoma: Friend or foe?. Surgery, 2015, 157 (4), pp.656-65. 10.1016/j.surg.2014.11.011 . hal-01132562

\section{HAL Id: hal-01132562}

\section{https://hal-univ-rennes1.archives-ouvertes.fr/hal-01132562}

Submitted on 6 May 2015

HAL is a multi-disciplinary open access archive for the deposit and dissemination of scientific research documents, whether they are published or not. The documents may come from teaching and research institutions in France or abroad, or from public or private research centers.
L'archive ouverte pluridisciplinaire HAL, est destinée au dépôt et à la diffusion de documents scientifiques de niveau recherche, publiés ou non, émanant des établissements d'enseignement et de recherche français ou étrangers, des laboratoires publics ou privés. 


\section{Extended liver resections for intrahepatic cholangiocarcinoma: Friend or foe?}

Bergeat $\mathrm{D}, \mathrm{MD}^{1,3^{*}}$, Sulpice L, MD., $P \mathrm{Ph}^{1,3^{*}}$, Rayar M, $M D^{1}$, Edeline J, MD ${ }^{2,3}$, Merdignac A, $\mathrm{MD}^{1,3}$ Meunier B, MD ${ }^{1}$, Boucher $\mathrm{E}, \mathrm{MD}^{2,3}$ and Boudjema K, MD., $\mathrm{PhD}^{1,3}$

${ }^{1}$ Service de Chirurgie Hépatobiliaire et Digestive, Hôpital Pontchaillou, Centre Hospitalier Universitaire, Université de Rennes 1, Rennes, France

${ }^{2}$ Service d'Oncologie Médicale, CRLCC, Université de Rennes 1, Rennes, France

${ }^{3}$ INSERM, UMR991. Foie, métabolisme et cancer. Université de Rennes1, Rennes, France

* The two first authors contributed equally to this manuscript and should be considered cofirst authors.

Running title: Extended liver resection for ICC

Correspondence:

Doctor Laurent Sulpice and Professor Karim Boudjema

Service de Chirurgie Hépatobiliaire et Digestive, Hôpital Pontchaillou, Centre Hospitalier

Universitaire, Université de Rennes 1, Rennes, France

Telephone: + 33299284265 Fax: + 33299284129

Email: laurent.sulpice@chu-rennes.fr - karim.boudjema@chu-rennes.fr

Keywords: extended Liver resection, intrahepatic cholangiocarcinoma, outcomes, survival

Conflicts of interest: The authors have no conflicts of interest to declare.

Funding: The study received no external support.

Category of submission: Original article

World count: 2659 


\section{SHORT SUMMARY:}

Extended hepatic resections for intrahepatic cholangiocarcinoma is an independent risk factor for major complication but do not affect negatively oncologic outcomes. The importance of oncologic results of extended hepatic resections is that such resections could be performed for large tumors and may be in second line of treatment for patients with initially unresectable tumors. 


\section{ABSTRACT}

BACKGROUND: In patients with intrahepatic cholangiocarcinoma (ICC), extended liver resections (ELRs) increase the rate of resectability. The aims of the present study were to evaluate the morbidity and oncologic outcomes of ELR compared with other liver resections (LR) for ICC.

METHODS: All LR for ICC that were performed in our center between January 1997 and September 2013 and conducted with curative intent were included in this retrospective analysis. ELRs were defined by resections of $\geq 5$ liver segments. The factors that influenced the occurrence of major complications (Clavien $\geq 3$ ) and overall survival were tested with uni- and multivariate analyses.

RESULTS: One hundred and seven patients (82 men and 25 women) were resected, and 27 (25.3\%) underwent ELRs. Compared with the LRs, the ELRs were performed in larger tumors $(p=0.003)$ and were significantly associated with more complex surgeries such as vascular $(p<0.001)$ or biliary reconstructions $(p<0.001)$. Multivariate analysis revealed that ELR was an independent risk factor for major complications (OR 6.2, [2.11 to 19.62], $\mathrm{p}<0.001$ ). Compared with the other LRs, ELRs had no effects on overall survival (OS) or disease-free survival $(p=0.881$ and $p=0.228$, respectively). Perioperative blood transfusion (OR 2.51, [1.49 to 4.23], $p<0.001$ ), the presence of more than one nodule (OR 3.17, [1.67 to 5.97], $p<0.001$ ) and an age $\geq$ 65 years (OR 1.72, [1.03 to 2.86)], $p=0.036$ ) were independent prognostic factors for overall survival.

CONCLUSIONS: This study suggests that ELRs performed for large ICCs do not negatively affect oncological outcomes despite the increased risk of major complications. 


\section{INTRODUCTION}

Liver resection (LR) is the most suitable curative treatment for intrahepatic cholangiocarcinoma (ICC). ICC has become a public health issue with an incidence that has increased in all Western countries in the last two decades ${ }^{1-4}$. Moreover, the prognosis for ICC has not or only slightly improved. Indeed, the median survival ranges between 18 and 39 months ${ }^{5,6}$.

This poor prognosis is first related to the high rate of recurrence, particularly during the first year following liver resection ${ }^{7}$, and to the low rate of resectability. Indeed, in the majority of cases, ICC arises in patients without identifiable underlying liver disease and is thus frequently diagnosed at a late stage with large tumors ${ }^{8-10}$. In these conditions, the only available curative resection options are extended liver resections (ELR) or orthotopic liver transplantation (OLT). Unfortunately, the first studies that reported on the primary results of OLT in ICC revealed five-year overall survival (OS) rate of only $25 \%{ }^{11}$. These poor results are inconceivable in periods of liver graft scarcity. In contrast, with the recent progress in surgical techniques, perioperative management and postoperative care, ELR has become increasingly common, and the risks associated with these major procedures have decreased. For example, portal vein occlusion via ligation or embolization allows for the possibility of increasing the remaining liver and thus reducing the risk of liver failure following ELR. In recent years, our experiences have revealed an increase in the indications for ELR in ICC from $17 \%$ to one-third of cases (Figure 1.). However, this surgical aggressiveness has not yet been evaluated. Although some reports have analyzed the effects of vascular reconstruction on survival and outcome ${ }^{12}$, none have specifically compared ELR and LR in terms of outcomes and survival.

The aim of the present study was to analyze the outcomes and survival following LR with curative intent for ICC with a special focus on ELR. 


\section{METHODS}

\section{Patients}

The study population included all with curative-intent LRs performed for mass forming type ICCs as defined by the liver Cancer Study Group of Japan at a single tertiary referral center between the 1st of January 1997 and the 1st of September 2013. Hepatocellular cholangiocarcinoma, gallbladder carcinoma, hilar cholangiocarcinoma and periductal infiltrating types were excluded from the analyses. The clinical data were retrospectively collected from an LR database and analyzed after institutional review board approval was obtained.

Data were collected regarding demographics (i.e., age, sex and body mass index $(\mathrm{BMI})$ ), surgical variables, length of hospital stay, morbidity, postoperative chemotherapy and follow-up including disease recurrence and death.

Pathological data, such as the tumor size, satellite nodes, lymph node involvement, UICC $7^{\text {th }}$ edition TNM staging, perineural invasion and microvascular involvement, were collected.

\section{Surgery}

Prior to surgery, each patient was evaluated by thoracoabdominal computed tomography scans with intravenous contrast. Portal vein embolization was indicated when the Liver Resection Volume/total liver volume ratio was < 35\%. Extended liver resection (ELR) was defined by the resection of five or more Couinaud liver segments. Right or left hepatectomy extended to segment 1 and right or left trisectionectomy were considered to be ELRs. All LRs were performed with curative intent by senior surgeons. Intraoperative ultrasounds of the liver were performed to ensure the extension and the resectability of the tumor. Vascular or biliary reconstructions (partial or complete) were performed when necessary. Vascular reconstructions were classified into the following three categories: portal vein reconstruction, inferior vena cava reconstruction, and hepatic artery reconstruction. In one case, LR was performed ex situ. The absence of bulky lymph nodes in the celiac or paraaortic area, the absence of tumor residue in the remnant liver and the absence of peritoneal extension defined curative hepatectomies. The resection 
margin was classified as microscopically negative (R0) or positive (R1). When macroscopic tumoral tissue was left in situ, the resection was R2.

\section{Postoperative morbidity}

Postoperative morbidity was defined by any complication that occurred within 90 days after the LR and was categorized according to the Dindo and Clavien classification $^{13}$. Major complications (MC) were categorized as grades III to $\mathrm{V}$ in the Dindo and Clavien classification. Postoperative liver failure was defined by the "5050 " criteria on postoperative day 5 as described by Balzan et al. ${ }^{14}$. Postoperative mortality was defined by the occurrence of death within 90 postoperative days.

\section{Survival Analyses}

The end of the follow-up was set to be between the $1^{\text {st }}$ of December 2013 and the $1^{\text {st }}$ of January 2014 or the time of death. Overall survival was calculated from the date of the intervention to the time of death (regardless of cause) or to the end of follow-up. Disease-free survival (DFS) was calculated from the date of the intervention to the time of recurrence or the time of death. To identify the prognostic factors for overall survival, the following data were analyzed: age, gender, ASA score $\geq 2$, BMI ranking in categories $(<25,25-30$ and $>30)$, known cirrhosis, neoadjuvant chemotherapy, portal embolization, ELR, vascular resection, bile duct resection, lymph node dissection, resectability, perioperative blood transfusion, major complications, tumor size $(\geq 5 \mathrm{~cm}), \geq 1$ node, macrovascular invasion, perineural invasion, positive lymph nodes, and adjuvant chemotherapy.

\section{Statistical Analyses}

Comparisons were made between the patients who underwent ELR and those who underwent other LRs. Qualitative variables are expressed as numbers with percentages and were compared with chi square tests or Fisher's tests when necessary. Quantitative variables are expressed as the mean \pm the standard deviation (SD) or the median and were compared using Student's t tests or MannWhitney $U$ tests as appropriate. Univariate analyses were conducted on the variables that are known to have roles in postoperative major complications. All variables with $p$ values $<0.1$ in the univariate analyses were entered into the multivariate analysis 
that utilized a multiple logistic regression model. The most suited model was then selected using a stepwise method based on the Akaike criteron.

The cumulative survival rate was estimated by the Kaplan-Meier method, and the survival curves were compared with the log rank test. The univariate analyses were conducted between the relevant clinicopathologic variables and the cumulative survival rates using the log rank test. The Cox proportional hazard model was utilized with all variables with $p$ values $<0.1$ in the univariate analyses and the variables that are known to influence survival. Stepwise method was also used to select the most suited model. $\mathrm{P}<0.05$ was considered statistically significant in all comparisons. The analyses were performed with R statistical software (http://www.r-project.org/). 


\section{RESULTS}

\section{Demographic and operative data}

During the study period, 107 patients underwent LR with curative intent for ICC (82 men and 25 women). ELR was performed in 27 cases (25\%). The preoperative data were compared and are shown in the Table 1 . The mean ages were $61.4 \pm 10.2$ years and $65.6 \pm 8.9$ years in the ELR and other LR groups, respectively $(p=0.07)$. The patients' BMls were greater than 30 in three cases $(11.11 \%)$ in the ELR group and in 21 cases in the other group (26.25\%; $p=0.2)$. No differences were found in either portal vein embolization or neoadjuvant chemotherapy rates between the two groups. The tumor size was significantly larger in the ELR than in the other LR group (7.8 $\pm 2.46 \mathrm{~cm}$ vs. $6.14 \pm 3.14$, respectively, $\mathrm{p}=0.003)$. ELRs were associated with more complex reconstructions. Indeed, vascular reconstructions were required in eight cases (29.63\%) in the ELR group vs. three (3\%) in the other LR group $(p<0.001)$, and included portal vein reconstructions in six vs. one $(p<0.001)$, inferior vena cava reconstructions in four vs. two $(p=0.03)$ and hepatic artery reconstructions and in three vs. zero $(p=0.01)$ of the cases in each respective group. Bile duct resections were required for eight patients (29.63\%) in the ELR and two (2.5\%) patients in the other LR group $(p<0.001)$.

R0 resection rate was similar in both group (74\% vs $79 \%$ in ELR and other LR group respectively, $p=0.81$ ).

The major complication and surgical revision rates were significantly higher in the ELR group than in the other LR group (59.26 vs. $15 \%(p=0.01)$ and 29.63 vs. $7.5 \%$ $(p=0.06)$, respectively). The liver dysfunction rates were not statistically different (7.41 and 10\% in the ELR and other LR group, respectively).

Hospital stay was significantly longer in ELR group than in other LR group ( $13 \pm 16.7$ days [4-70] and $10 \pm 13.3$ days [4-91], respectively $(p=0.02)$.

The 90-day mortality rate was $9.2 \%$ (10 patients) across the entire population, and there was no difference between the two groups $(p=1)$. We have summarized all causes of death in the Supplementary Table 1. Two patients $(7.4 \%)$ in the ELR group died; the first death was linked to portal vein and arterial thromboses following an extended right hepatectomy, and the second was linked to major sepsis. 


\section{Risk Factors for Major Complications}

Twenty-eight patients developed major complications (26\%). Among the 14 factors assessed by univariate analyses (Table 2.), ELR $(\mathrm{p}<0.001)$, vascular reconstruction $(p<0.001)$, bile duct resection $(p=0.02)$ and extended lymphadenectomy $(p=0.01)$ were significantly associated with increased risks of major complication. In the multivariate analysis, ELR $(\mathrm{OR}=6.2,(2.11-19.62), \mathrm{p}<0.001)$ was the only remaining independent risk factor for major complications.

\section{Survival and recurrence analyses}

All patients were included in the overall and disease-free survival analyses. The median overall survival of the entire cohort was 32.8 months, and the one-, threeand five-year actuarial survival rates were $79.8,49.4$ and $34.6 \%$, respectively.

Recurrence was observed in 16 ELR patients (59.26\%) and 44 other LR patients $(55 \% ; p=0.81)$. Fifty-five percent of the recurrences were at least intrahepatic. The median disease-free survival of the entire cohort was 10.73 months, and the one-, three- and five-year actuarial survival rates were 49.68, 25.7 and $17.4 \%$, respectively. The overall survival rates and disease-free survival rates were not significantly different between the ELR and the other LR groups, $p=0.881$ and $p=0.228$, respectively; Figure 2.

\section{Univariate and Multivariate Analysis of Variables Affecting Overall Survival}

The variables that were thought to have effects on overall survival are reported in Table 3. Extended lymphadenectomy $(p=0.05)$, perioperative allogenic blood transfusion $(p<0.001)$, tumor size $\geq 5 \mathrm{~cm}(p=0.005)$, multinodular tumor $(p<0.001)$ and positive lymph node involvement $(p=0.02)$ were associated with poor overall survival. Neither vascular reconstruction nor extended resection significantly affected overall survival. The multivariate analysis revealed that an age $\geq 65$ years (OR 1.72 , (1.03-2.86), $\mathrm{p}=0.036$ ), a perioperative blood transfusion (OR 2.51, (1.49 to 4.23), $p<0.001$ ) and the presence of more than one nodule (OR 3.17, (1.67 to 5.97), $\mathrm{p}<0.001$ ) were independent risk factors for overall survival (Figure 3). 


\section{DISCUSSION}

Liver resection with curative intent remains the best therapeutic option for ICC patients ${ }^{15}$. Advances in anesthesiology, liver surgery and postoperative care have enabled more extensive liver resections. The present study analyzed the outcomes of 27 ELRs that were performed with the intent to cure ICC patients. Our results are the first to shed light on the surgical aggressiveness of the use of ELR for ICC compared with the use of less aggressive LRs. Indeed, we demonstrated that, despite an increase in the 90-day postoperative major morbidity, ELR resulted OSs and DFSs that were similar to those of non-extended LRs that were performed for smaller tumors. These results are strengthened by the absence of patients lost to follow up in our cohort.

The multivariate analysis of the factors associated with major complications revealed that ELR was the only independent risk factor. In this series, the higher rate of $\mathrm{MC}$ in the ELR group was probably linked to the complexity of surgeries, which included more vascular or biliary resections and reconstructions. The most frequent complication was biliary leakage, and this finding accords with a finding of our previous report that showed that major LR was an independent risk factor for the occurrence of biliary leakage ${ }^{16}$. These results have recently been confirmed by Zimmity et al. in a large retrospective study of approximately 2628 LRs that showed that increased LR complexity is correlated with the rate of biliary leakage but not with the rates of hemorrhage or perihepatic abscesses ${ }^{17}$. In the present series, the overall 90-day mortality was higher than the recent report of Ali et al. ${ }^{12}$. This difference could be partially explained by the lack of selection criterion such as the age or underlying liver disease.

Although portal vein embolization (PVE) was considered preoperatively in all cases, two patients $(7.4 \%)$ in the ELR group who did not have PVEs developed postoperative liver dysfunction. These results are in line with those of a previously published study ${ }^{18,19}$. However, these findings might indicate that the operative risk was underestimated in the ICC patients, and therefore inadequate preoperative and operative management was applied. This underestimation is likely based on the false belief that ICCs arise in normal underlying liver parenchyma. Indeed, one might 
consider that the increased incidence of ICC in Western countries might be related to the rise of metabolic syndromes and insulin resistance ${ }^{3,20}$, which would lead us to believe that ICCs often occur in liver parenchyma with steatosis or steatohepatitis and might partially explain the rate of postoperative liver failure ${ }^{21}$.

Similarly, Cauchy et al. recently demonstrated that LR for HCC associated with metabolic syndrome is significantly associated with an elevated risk of postoperative morbidity $^{22}$. Based on these results, it is reasonable to suggest that improvements in pre- and perioperative management should be implement especially when ELR is considered for ICC.

The main result of the present study is that ELR performed for the largest ICC neither negatively influenced OS nor DFS compared with non-ELR performed for the smallest tumors. Indeed, the actuarial five-year OS of the patients who underwent ELR was $32.3 \%$, and this result is largely similar to those reported by Cho et al. in their series of 63 LRs for which the five-year cumulative survival rate was $31.8 \%{ }^{23}$. Beyond the fact that these results validate our aggressive policy, they allow us to further broaden the criteria for the patients who are eligible for curative treatments; specifically some patients with conditions currently considered unresectable could be included. Indeed, the challenge henceforth is to identify and validate therapeutic strategies that can reduce tumor size and enable curative resection through ELR. Among the different possibilities, transcatheter arterial chemoembolization (TACE) using cisplatin might represent a promising approach ${ }^{24}$. TACE allows for the delivery of increasing local concentrations of chemotherapy without damaging the healthy liver tissue and reduces systemic side effects ${ }^{24}$. Accordingly, Kim et al. reported interesting results about down-staging ICC following $\mathrm{TACE}^{25}$. Similarly, the intraarterial injection of yttrium-90-labeled (yttrium-90) is a persuasive therapeutic option that can decrease tumor and increase the remnant liver volume as has recently been shown in $\mathrm{HCC}^{26}$. We previously demonstrated the potential of yttrium-90 in ICC recurrence following primary curative resection to ensure prolonged survival ${ }^{7}$. Among 46 patients with ICCs that were initially considered unresectable, Mouli et al. reported that that $10.8 \%(n=5)$ were converted to resectable statuses and were successfully treated with curative resection after yttrium- $90{ }^{27}$. These results are reinforced by a recently published clinical case ${ }^{28}$. Altogether, expert centers play a crucial role in the management of ICC and contribute to the optimization of the management of these 
cancers especially when large cancers that are potentially unresectable and require collaboration between surgeons, oncologists and radiologists are being considered.

Finally, our multivariate analysis of the factors that affected the OS demonstrated that only an age over 65 years, the presence of satellite nodules and the requirement for a perioperative blood transfusion were closely correlated with the poorest prognoses. In this series, blood transfusions were required in $29.63 \%$ of the ELR group, which is not different from previously reported results ${ }^{19}$. Perioperative blood transfusion has been highlighted frequently as an important predictive factor for perioperative mortality and survival in liver cancer surgery for the last 20 years. A recent metaanalysis of the effects of perioperative blood transfusions in patients with hepatocellular carcinomas confirmed that perioperative blood transfusions are associated with an elevated risk of death at three and five years and an increased risk of tumor recurrence ${ }^{29}$. Several authors have argued that these effects are due to the immunosuppressive effects of blood transfusion and support the role of the immune system in the control of tumor proliferation and progression. Accordingly, it is important to reassert that perioperative allogenic blood transfusion should not be avoided when possible and to emphasize surgical techniques that minimize blood loss. These data further strengthen the need to manage these patients in expert centers to improve the overall prognoses of these tumors.

Obviously, the current study has some limitations. Even if there was no significant difference between the ELR group and the other LR group on confounding variables, there was potentials selection bias. The sample size of the ELR group was quite small even it represented a quarter of our entire population and further studies are needed to confirm the results.

In conclusion, for the first time, this study supports the notion that ELRs for large ICCs do not negatively affect oncological outcomes. These findings argue in favor of aggressive therapeutic strategies for ICC to increase the rate of resectability. In view of ELR results on survival, we can assume that the combination of a neoadjuvant therapy, such as yttrium-90, to decrease the tumor size and increase the remnant liver with ELR is an appealing strategy that should be explored in the near future. 


\section{REFERENCES}

1. Taylor-Robinson SD, Toledano MB, Arora S, Keegan TJ, Hargreaves S, Beck A, et al. Increase in mortality rates from intrahepatic cholangiocarcinoma in England and Wales 1968-1998. Gut. 2001 Jun 1;48(6):816-20.

2. Patel T. Increasing incidence and mortality of primary intrahepatic cholangiocarcinoma in the United States. Hepatology. 2001 Jun;33(6):1353-7.

3. Welzel TM, Graubard BI, El-Serag HB, Shaib YH, Hsing AW, Davila JA, et al. Risk Factors for Intrahepatic and Extrahepatic Cholangiocarcinoma in the United States: A Population-Based Case-Control Study. Clinical Gastroenterology and Hepatology. 2007 Oct;5(10):1221-8.

4. Wood R, Brewster DH, Fraser LA, Brown H, Hayes PC, Garden OJ. Do increases in mortality from intrahepatic cholangiocarcinoma reflect a genuine increase in risk? Insights from cancer registry data in Scotland. European Journal of Cancer. 2003 Sep;39(14):2087-92.

5. Farges O, Fuks D, Le Treut Y-P, Azoulay D, Laurent A, Bachellier P, et al. AJCC 7th edition of TNM staging accurately discriminates outcomes of patients with resectable intrahepatic cholangiocarcinoma. Cancer. 2011;117(10):2170-7.

6. Ribero D, Pinna A, Guglielmi A, et al. Surgical approach for long-term survival of patients with intrahepatic cholangiocarcinoma: A multi-institutional analysis of 434 patients. Arch Surg. 2012 Dec 1;147(12):1107-13.

7. Sulpice L, Rayar M, Boucher E, Pracht M, Meunier B, Boudjema K. Treatment of recurrent intrahepatic cholangiocarcinoma. Br J Surg. 2012 Dec;99(12):1711-7.

8. Lang $H$, Sotiropoulos GC, Frühauf NR, Dömland M, Paul A, Kind E-M, et al. Extended hepatectomy for intrahepatic cholangiocellular carcinoma (ICC): when 
is it worthwhile? Single center experience with 27 resections in 50 patients over a 5-year period. Ann Surg. 2005 Jan;241(1):134-43.

9. Yamanaka N, Okamoto E, Ando T, Oriyama T, Fujimoto J, Furukawa K, et al. Clinicopathologic spectrum of resected extraductal mass-forming intrahepatic cholangiocarcinoma. Cancer. 1995 Dec 15;76(12):2449-56

10. Suzuki H, Isaji S, Pairojkul C, Uttaravichien T. Comparative clinicopathological study of resected intrahepatic cholangiocarcinoma in northeast Thailand and Japan. J Hepatobiliary Pancreat Surg. 2000;7(2):206-11.

11. Hu X-X, Yan L-N. Retrospective analysis of prognostic factors after liver transplantation for intrahepatic cholangiocarcinoma in China: a single-center experience. Hepatogastroenterology. 2011 Aug;58(109):1255-9.

12. Ali SM, Clark CJ, Zaydfudim VM, Que FG, Nagorney DM. Role of Major Vascular Resection in Patients with Intrahepatic Cholangiocarcinoma. Ann Surg Oncol. 2013 Jun 1;20(6):2023-8.

13. Dindo D, Demartines N, Clavien P-A. Classification of Surgical Complications: A New Proposal With Evaluation in a Cohort of 6336 Patients and Results of a Survey. Annals of Surgery. 2004 Aug;240(2):205-13.

14. Balzan S, Belghiti J, Farges O, Ogata S, Sauvanet A, Delefosse D, et al. The ???50-50 Criteria??? on Postoperative Day 5: An Accurate Predictor of Liver Failure and Death After Hepatectomy. Annals of Surgery. 2005 Dec;242(6):8249. 
15. Farges O, Fuks D, Boleslawski E, Le Treut Y-P, Castaing D, Laurent A, et al. Influence of surgical margins on outcome in patients with intrahepatic cholangiocarcinoma: a multicenter study by the AFC-IHCC-2009 study group. Ann Surg. 2011 Nov;254(5):824-829; discussion 830.

16. Guillaud A, Pery C, Campillo B, Lourdais A, Laurent S, Boudjema K. Incidence and predictive factors of clinically relevant bile leakage in the modern era of liver resections. HPB (Oxford). 2013 Mar;15(3):224-9.

17.Zimmitti G, Roses RE, Andreou A, Shindoh J, Curley SA, Aloia TA, et al. Greater Complexity of Liver Surgery is Not Associated with an Increased Incidence of Liver-Related Complications Except for Bile Leak: An Experience with 2,628 Consecutive Resections. J Gastrointest Surg [Internet]. 2013 Jan [cited 2014 Feb 26];17(1). Available from: http://www.ncbi.nlm.nih.gov/pmc/articles/PMC3855461/

18. Ohtsuka M, Ito H, Kimura F, Shimizu H, Togawa A, Yoshidome H, et al. Results of surgical treatment for intrahepatic cholangiocarcinoma and clinicopathological factors influencing survival. Br J Surg. 2002 Dec 1;89(12):1525-31.

19. Vauthey J-N, Pawlik TM, Abdalla EK, Arens JF, Nemr RA, Wei SH, et al. Is Extended Hepatectomy for Hepatobiliary Malignancy Justified? Ann Surg. 2004 May;239(5):722-32.

20. Jing W, Jin G, Zhou X, Zhou Y, Zhang Y, Shao C, et al. Diabetes mellitus and increased risk of cholangiocarcinoma: a meta-analysis. Eur J Cancer Prev. 2012 Jan;21(1):24-31.

21. Reddy SK, Hyder O, Marsh JW, Sotiropoulos GC, Paul A, Alexandrescu S, et al. Prevalence of nonalcoholic steatohepatitis among patients with resectable intrahepatic cholangiocarcinoma. J Gastrointest Surg. 2013 Apr;17(4):748-55. 
22. Cauchy F, Zalinski S, Dokmak S, Fuks D, Farges O, Castera L, et al. Surgical treatment of hepatocellular carcinoma associated with the metabolic syndrome. $\mathrm{Br}$ J Surg. 2013 Jan;100(1):113-21.

23. Cho SY, Park S-J, Kim SH, Han S-S, Kim Y-K, Lee K-W, et al. Survival Analysis of Intrahepatic Cholangiocarcinoma After Resection. Ann Surg Oncol. 2010 Jul 1;17(7):1823-30.

24. Liapi E, Geschwind J-FH. Transcatheter and ablative therapeutic approaches for solid malignancies. J Clin Oncol. 2007 Mar 10;25(8):978-86.

25. Kim JH, Yoon H-K, Sung K-B, Ko G-Y, Gwon DI, Shin JH, et al. Transcatheter arterial chemoembolization or chemoinfusion for unresectable intrahepatic cholangiocarcinoma. Cancer. 2008 Oct 1;113(7):1614-22.

26. Edeline J, Lenoir L, Boudjema K, Rolland Y, Boulic A, Le Du F, et al. Volumetric changes after (90)y radioembolization for hepatocellular carcinoma in cirrhosis: an option to portal vein embolization in a preoperative setting? Ann Surg Oncol. 2013 Aug;20(8):2518-25.

27. Mouli S, Memon K, Baker T, Benson III AB, Mulcahy MF, Gupta R, et al. Yttrium90 Radioembolization for Intrahepatic Cholangiocarcinoma: Safety, Response, and Survival Analysis. Journal of Vascular and Interventional Radiology. 2013 Aug;24(8):1227-34.

28. Servajean C, Gilabert M, Piana G, Monges G, Delpero J-R, Brenot I, et al. One case of intrahepatic cholangiocarcinoma amenable to resection after radioembolization. World J Gastroenterol. 2014 May 7;20(17):5131-4.

29. Liu L, Wang Z, Jiang S, Shao B, Liu J, Zhang S, et al. Perioperative Allogenenic Blood Transfusion Is Associated with Worse Clinical Outcomes for Hepatocellular 
Carcinoma: A Meta-Analysis. Hills RK, editor. PLoS ONE. 2013 May 31;8(5):e64261. 


\section{TABLE AND FIGURE LEGENDS}

Table 1. Patient characteristics, perioperative data and outcomes according to extended resection status.

Table 2. Factors influencing the occurrence of major complications.

Table 3. Factors influencing the overall survival.

Figure 1. Evolution of the frequency with which ELR were performed before and after 2008.

Figure 2. Overall and disease-free survival rates after liver resection according to extended liver resection (ELR) status (continuous line: non-ELR, dotted line: ELR).

Figure 3. Overall survival after liver resection according to transfusion status (continuous line: no transfusion, dotted line: transfusion) and the presence of more than one nodule (continuous line: 1 nodule, dotted line: $>1$ nodule).

Supplementary Table 1. Summarized of 90-day mortality causes. 


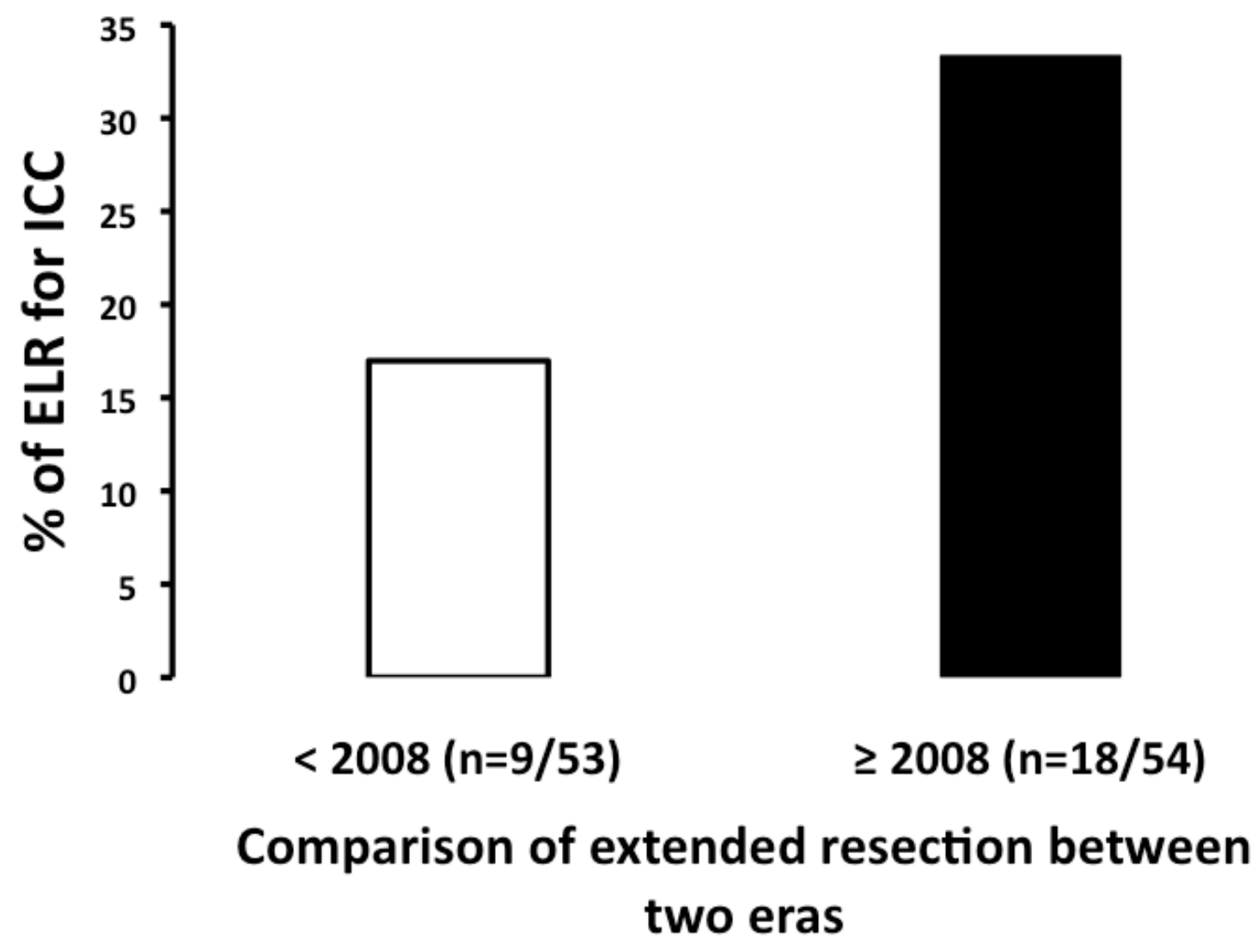

Figure 1. Evolution of the frequency with which ELR were performed before and after 2008. 

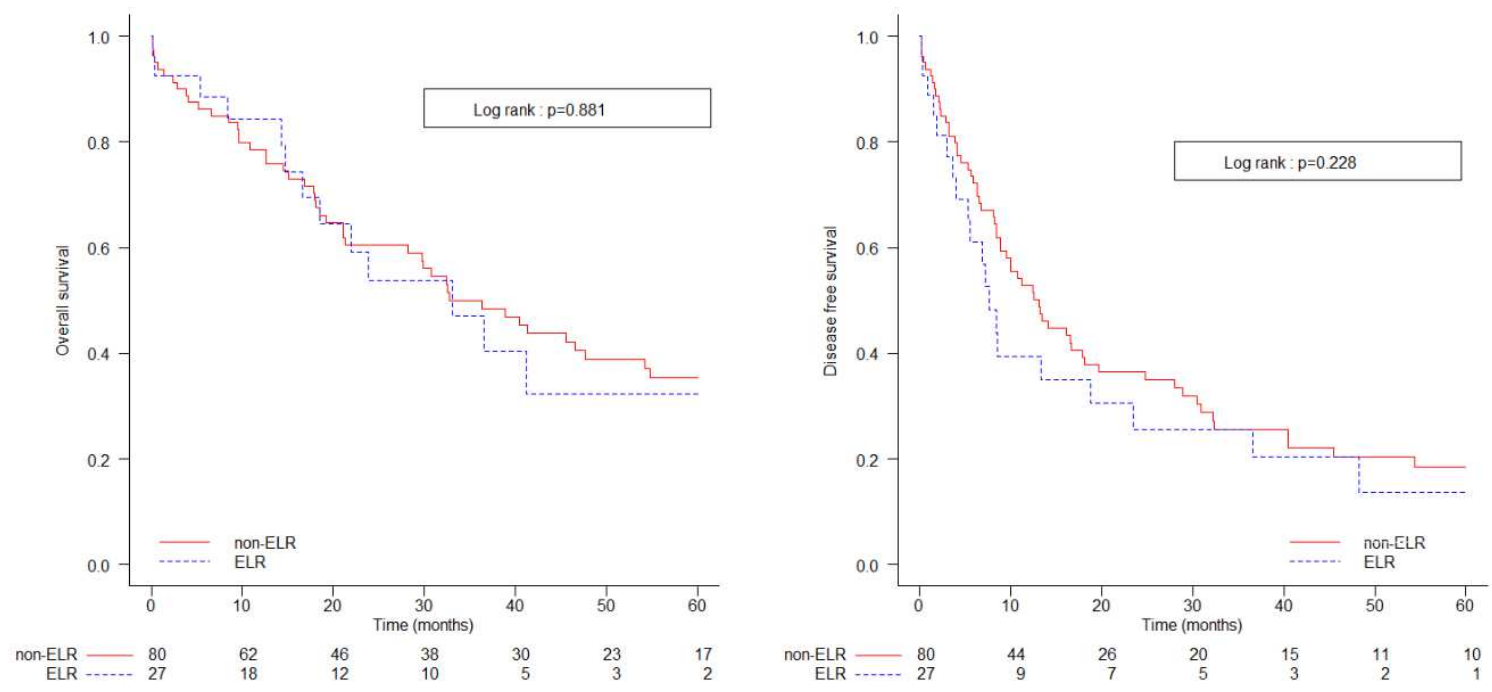

Figure 2. Overall and disease-free survival after liver resection according to extended liver resection status (ELR) (continuous line: non-ELR, dotted line: ELR). 

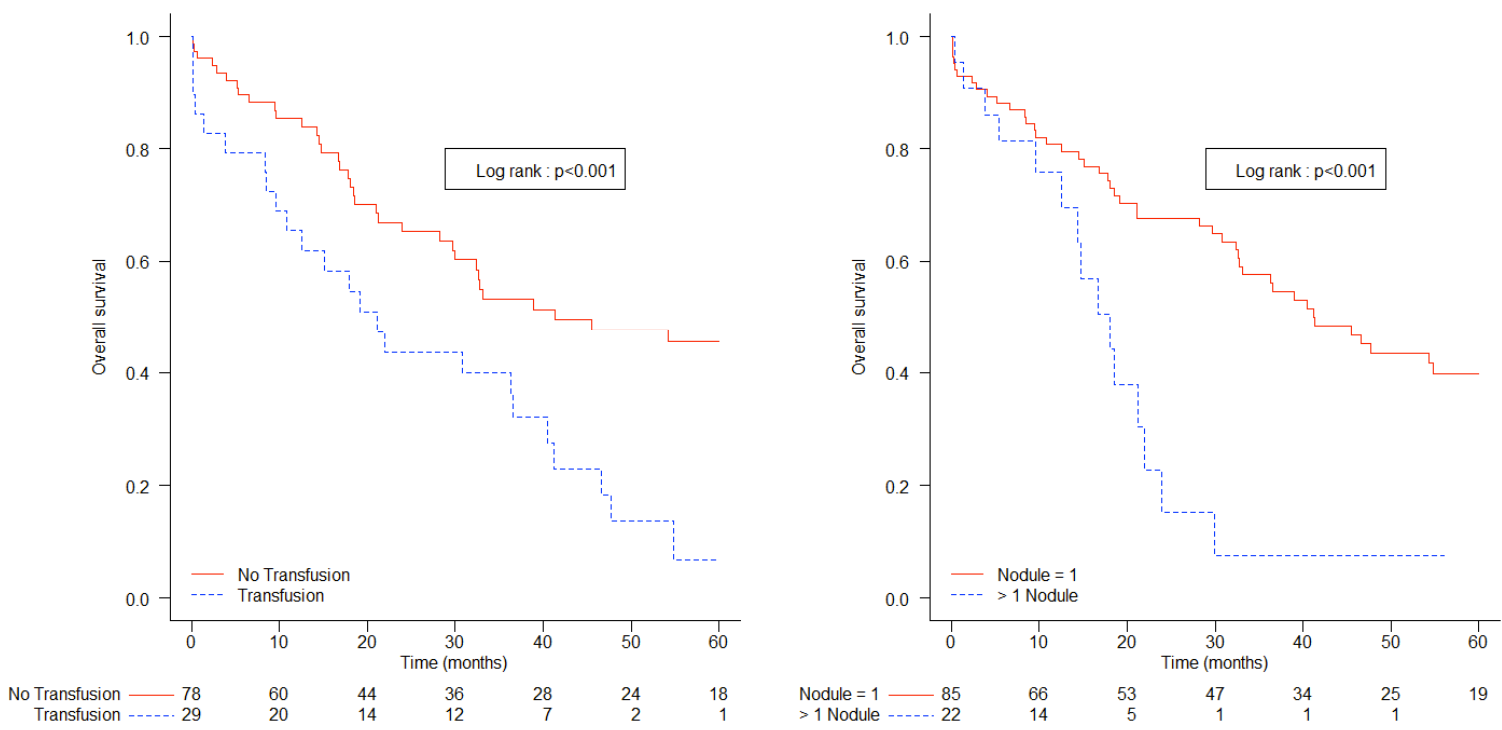

Figure 3. Overall survival after liver resection according to transfusion status (continuous line: no transfusion, dotted line: transfusion) and the presence of more than one nodule (continuous line: nodule $=1$, dotted line: $>1$ nodule). 
Table 1.

Patient characteristics, Perioperative and outcome data according to extended resection status

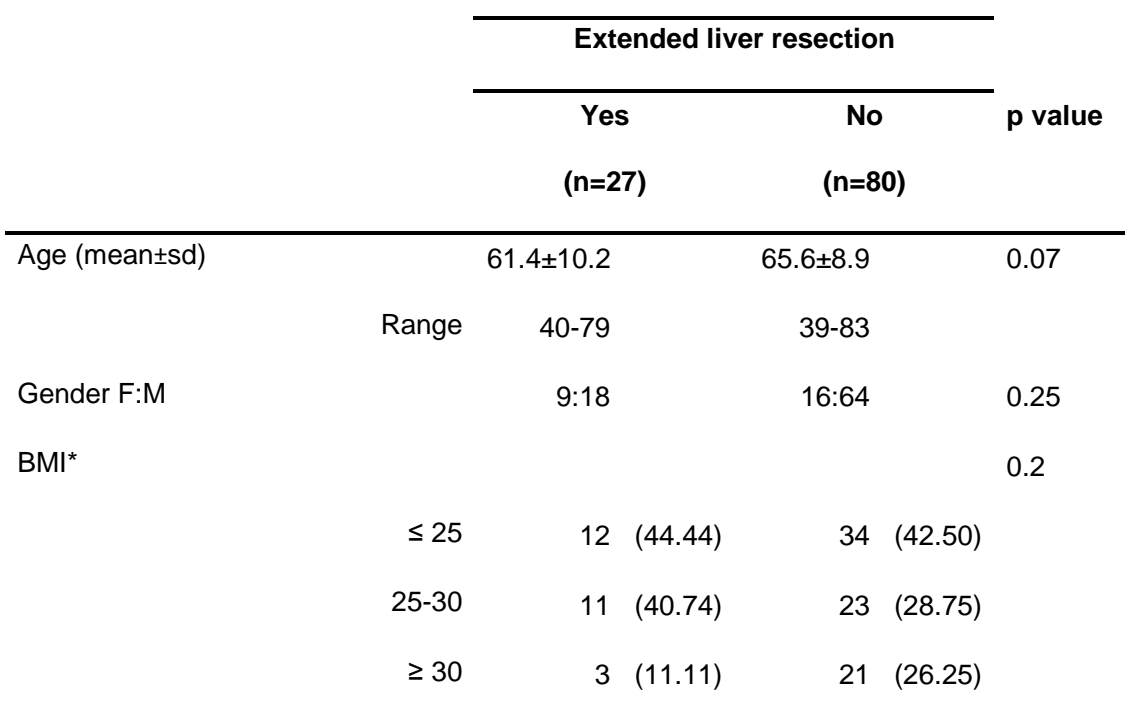

ASA score**

\begin{tabular}{|c|c|c|c|c|c|}
\hline$<2$ & 21 & $(77.78)$ & 62 & $(77.50)$ & \\
\hline$\geq 2$ & 6 & (22.22) & 16 & $(20.00)$ & \\
\hline Known cirrhosis & 4 & (14.81) & 25 & $(31.25)$ & 0.14 \\
\hline Portal embolization & 6 & (22.22) & 8 & $(10.00)$ & 0.18 \\
\hline Neoadjuvant chemotherapy & 6 & (22.22) & 9 & $(11.25)$ & 0.19 \\
\hline Blood transfusion & 8 & (29.63) & 21 & $(26.25)$ & 0.9 \\
\hline \multicolumn{6}{|l|}{ Vascular resection } \\
\hline Portal vein resection & 6 & (22.22) & 1 & $(1.25)$ & $<0.001$ \\
\hline Inferior vena cava resection & 4 & $(14.81)$ & 2 & $(2.50)$ & 0.03 \\
\hline Hepatic artery resection & 3 & $(11.11)$ & 0 & $(0.00)$ & 0.01 \\
\hline Bile duct resection & 8 & (29.63) & 2 & (2.50) & $<0.001$ \\
\hline Resectability & & & & & 0.81 \\
\hline Ro & 20 & $(74.07)$ & 63 & $(78.75)$ & \\
\hline R1 & 7 & (25.93) & 17 & $(21.25)$ & \\
\hline Tumor size $(\mathrm{cm}$, mean $\pm \mathrm{sd})$ & $7.8 \pm 2.46$ & & $\begin{array}{r}6.14 \pm \\
3.14\end{array}$ & & 0.003 \\
\hline 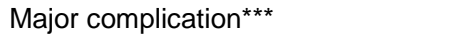 & 16 & $(59.26)$ & 12 & $(15.00)$ & $<0.001$ \\
\hline Biliary fistulas & 10 & $(37.04)$ & 11 & $(13.75)$ & 0.01 \\
\hline Surgical revision & 8 & (29.63) & 6 & $(7.50)$ & 0.006 \\
\hline Hospital stay (days, median $\pm s d$ ) & $13 \pm 16.7$ & & $10 \pm 13.3$ & & 0.02 \\
\hline Range & $4-70$ & & $4-91$ & & \\
\hline
\end{tabular}




$\begin{array}{lllll}\text { Yes } & 16 & (59.26) & 44 & (55.00) \\ \text { No } & 10 & (37.04) & 34 & (42.50)\end{array}$

90d mortality

Recurrence

2 (7.41)

$\begin{array}{lll}8 & (10.00) & 1\end{array}$
0.81

${ }^{*} 3 \mathrm{NA},{ }^{* *} 2 \mathrm{NA},{ }^{* \star *}$ Clavien $\geq 3$ 
Table 2.

Univariate and Multivariate analyses of major complications factors

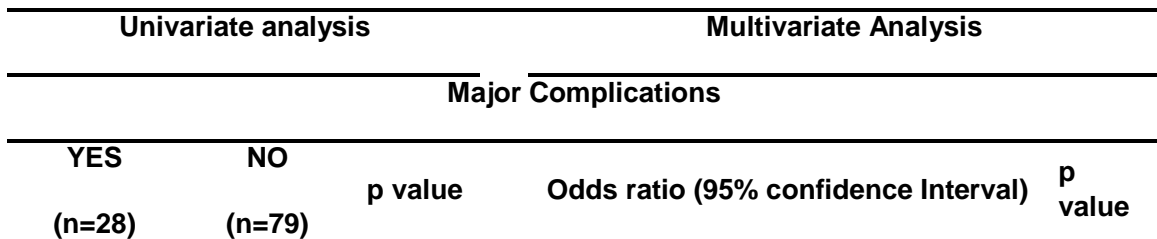

Age 0.39

$\begin{array}{llllll}<65 & & 15 & (53.57) & 33 & (41.77) \\ \geq 65 & & 13 & (46.43) & 46 & (58.23)\end{array}$

Gender

$\begin{array}{rrrrr}\text { Male } & 18 & (64.29) & 64 & (81.01) \\ \text { Female } & 10 & (35.71) & 15 & (18.99)\end{array}$

$\mathrm{BMI}^{*}$

$$
\begin{aligned}
& \begin{array}{lllll}
\leq 25 & 14 & (50.00) & 32 & (40.51)
\end{array} \\
& \text { 25-30 } \quad 7 \quad(25.00) \quad 27 \quad(34.18) \\
& \begin{array}{lllll}
\geq 30 & 5 & (17.86) & 19 & (24.05)
\end{array}
\end{aligned}
$$

ASA score ${ }^{\star \star}$

$$
\begin{aligned}
& <2 \quad 4 \quad(14.29) \quad 18 \quad(22.78) \\
& \geq 2 \quad 23 \quad(82.14) \quad 60 \quad(75.95)
\end{aligned}
$$

Known cirrhosis

$\begin{array}{llllll}\text { Yes } & & 4 & (14.29) & 25 & (31.65) \\ \text { No } & & 24 & (85.71) & 54 & (68.35)\end{array}$

Neo adjuvant chemotherapy

$$
\begin{aligned}
& \text { Yes } \quad 5 \quad(17.86) \quad 10 \quad(12.66) \\
& \begin{array}{lllll}
\text { No } & 23 & (82.14) & 69 & (87.34)
\end{array}
\end{aligned}
$$

Portal embolization

$$
\begin{aligned}
& \begin{array}{lllll}
\text { Yes } & 3 & (10.71) & 11 & (13.92)
\end{array} \\
& \begin{array}{lllll}
\text { No } & 25 & \text { (89.29) } & 68 & (86.08)
\end{array}
\end{aligned}
$$

Operative time

$$
\begin{array}{lllll}
\geq 180 \min & 13 & (46.43) & 32 & (40.51) \\
<180 \min & 15 & (53.57) & 66 & (83.54)
\end{array}
$$

Tumor size

$$
\begin{array}{lrrrr}
<5 \mathrm{~cm} & 4 & (14.29) & 30 & (37.97) \\
\geq 5 \mathrm{~cm} & 24 & (85.71) & 49 & (62.03)
\end{array}
$$

Blood transfusion 
Extended liver resection

$$
<0.001
$$

6.2(2.11-19.62)

$<0.001$

$\begin{array}{lllll}\text { Yes } & 16 & (57.14) & 11 & (13.92) \\ \text { No } & 12 & (42.86) & 68 & (86.08)\end{array}$

Vascular resection

$$
\begin{aligned}
& \text { Yes } \quad \begin{array}{llll}
8 & (28.57) & 3 & (3.80)
\end{array} \\
& \text { No } \quad 20 \quad(71.43) \quad 76 \quad(96.20)
\end{aligned}
$$

Bile duct resection

Yes $\quad \begin{array}{llll}6 & (21.43) \quad 4 & (5.06)\end{array}$

No $\quad 25$ (89.29) 75 (94.94)

Extended

lymphadenectomy

\begin{tabular}{|c|c|c|}
\hline Yes & $16(57.14)$ & 22 \\
\hline No & $12(42.86)$ & 57 \\
\hline
\end{tabular}

Resectability

$$
\begin{aligned}
& \text { Ro } \quad 19 \quad(67.86) \quad 64 \quad(81.01) \\
& \mathrm{R} 1 \quad 9 \quad(32.14) \quad 15 \quad(18.99)
\end{aligned}
$$


Table 3.

Risk factors for overall survival

Factors

Univariate Analysis Multivariate Analysis

\begin{tabular}{lrrrrrrr} 
& & $\mathbf{1} y$ & $\mathbf{3} \mathbf{y}$ & $\mathbf{5} \mathbf{y}$ & & $\mathbf{n}(\%)$ \\
\hline Age & & & & & & & \\
& $<5$ & 86.8 & 60.5 & 39.6 & 48 & $(44.86)$ \\
& $\geq 65$ & 70.6 & 41 & 30.9 & 59 & $(55.14)$ \\
Gender & & & & & & \\
& F & 71.1 & 44 & 36.7 & 25 & $(23.36)$ \\
& M & 79.6 & 50.6 & 34.2 & 82 & $(76.64)$
\end{tabular}

$\mathrm{BMI}$ *

$$
\begin{array}{rrrrrr}
\leq 25 & 73.4 & 59.7 & 43.1 & 46 & (42.99) \\
25-30 & 93.7 & 39.4 & 22.5 & 34 & (31.78) \\
\geq 30 & 78.9 & 47.8 & 38.3 & 24 & (22.43)
\end{array}
$$

Known cirrhosis

$$
\begin{array}{rrrrrr}
\text { Yes } & 79.3 & 40.9 & 31.8 & 29 & (27.10) \\
\text { No } & 81 & 53.6 & 36.4 & 78 & (72.90)
\end{array}
$$

Neo adjuvant

chemotherapy

$$
\begin{array}{llllll}
\text { Yes } & 71.8 & 53.8 & 21.5 & 15 & (14.02) \\
\text { No } & 81.1 & 48.6 & 36.3 & 92 & (85.98)
\end{array}
$$

Portal embolization

$$
\begin{array}{rrrrrr}
\text { Yes } & 77.9 & 33.4 & 11 & 14 & (13.08) \\
\text { No } & 80 & 51.1 & 37.4 & 93 & (86.92)
\end{array}
$$

Extended liver resection

$$
\begin{array}{llllll}
\text { Yes } & 84.3 & 47 & 32.3 & 27 & (25.23) \\
\text { No } & 78.5 & 50 & 35.3 & 80 & (74.77)
\end{array}
$$

Vascular resection

$$
\begin{array}{cccccc}
\text { Yes } & 64.9 & 64.9 & 43.3 & 11 & (10.28) \\
\text { No } & 78.8 & 48.4 & 34.2 & 96 & (89.72)
\end{array}
$$

Bile duct resection

$$
\begin{array}{llllll}
\text { Yes } & 77.1 & 61.7 & 41.1 & 10 & (9.35) \\
\text { No } & 79.9 & 48.3 & 34.1 & 97 & (90.65)
\end{array}
$$

Extended

lymphadenectomy

$$
\begin{array}{rrrrrr}
\text { Yes } & 74.6 & 37.3 & 17.5 & 38 & (35.51) \\
\text { No } & 82.5 & 55 & 41.9 & 69 & (64.49)
\end{array}
$$

Resectability 
$\begin{array}{llllll}\mathrm{R} 1 & 75 & 40.6 & 27.1 & 24 & (22.43)\end{array}$

Blood transfusion

Major complications

$\begin{array}{rrrrrr}\text { Yes } & 59.6 & 50 & 19 & 28 & (26.17) \\ \text { No } & 86.9 & 49.9 & 39.5 & 79 & (73.83)\end{array}$

Tumor size

0.0056

$$
\begin{array}{rrrrrr}
<5 \mathrm{~cm} & 91 & 76.7 & 51.6 & 34 & (31.78) \\
\geq 5 \mathrm{~cm} & 71.4 & 36.7 & 26.7 & 73 & (68.22)
\end{array}
$$

Nodule

$$
\begin{array}{rrrrrr}
1 & 80 & 57.6 & 39.9 & 85 & (79.44) \\
>1 & 75.9 & 7.6 & 0 & 22 & (20.56)
\end{array}
$$

Macrovascular invasion

$$
\begin{array}{rrrrrr}
\text { Yes } & 75.5 & 36.7 & 0 & 14 & (13.08) \\
\text { No } & 80.3 & 51 & 37.8 & 93 & (86.92)
\end{array}
$$

Microvascular invasion

$$
\begin{array}{llllll}
\text { Yes } & 69.4 & 34.1 & 26.3 & 42 & (39.25) \\
\text { No } & 86.1 & 58.6 & 39.3 & 65 & (60.75)
\end{array}
$$

Perineural invasion

$$
\begin{array}{rrrrrr}
\text { Yes } & 77.9 & 48.2 & 32.2 & 25 & (23.36) \\
\text { No } & 79.9 & 50 & 35.3 & 80 & (74.77)
\end{array}
$$

Positiv lymph nodes

$$
\begin{array}{rrrrrr}
\text { Yes } & 84.1 & 22.5 & 7.5 & 20 & (18.69) \\
\text { No } & 78.9 & 55.5 & 40.6 & 87 & (81.31)
\end{array}
$$

Adjuvant chemotherapy $\begin{array}{llllll}\text { Yes } & 87.1 & 31.3 & 15.7 & 17 & (15.89)\end{array}$

$\begin{array}{llllll}\text { No } & 78.4 & 51.7 & 36.8 & 90 & (84.11)\end{array}$ 
Supplementary Table 1. Summarized of 90-day mortality causes.

\begin{tabular}{llllc} 
Groupe & Age/Gender & $\begin{array}{c}\text { Underlying } \\
\text { liver disease }\end{array}$ & \multicolumn{1}{c}{ Cause(s) of death } & $\begin{array}{c}\text { Time of Death } \\
\text { (days after } \\
\text { surgery) }\end{array}$ \\
\hline Other LR & $67 / \mathrm{M}$ & Cirrhosis & Pulmonary infection & 42 \\
Other LR & $64 / \mathrm{F}$ & - & Biliary leakage and sepsis & 20 \\
Other LR & $77 / \mathrm{M}$ & - & Biliary leakage and sepsis & 86 \\
Other LR & $72 / \mathrm{M}$ & - & Liver failure & 7 \\
Other LR & $72 / \mathrm{M}$ & - & NA & 70 \\
Other LR & $83 / \mathrm{M}$ & Cirrhosis & Liver failure and pulmonary infection & 5 \\
Other LR & $75 / \mathrm{F}$ & - & Massive hemorrhage & 13 \\
Other LR & $81 / \mathrm{M}$ & - & Cardiac failure & 4 \\
\hline & & & & 4 \\
\hline ELR & $64 / \mathrm{F}$ & - & Portal vein and hepatic arterial thrombosis & 10 \\
\hline ELR & $72 / \mathrm{M}$ & Cirrhosis & Wound infection with major sepsis & \\
\hline
\end{tabular}

ELR $=$ Extended Liver Resection $; \mathrm{LR}=$ Liver resection ; $\mathrm{M}=$ Male ; F=Female 